\title{
O saber histórico e a experiência estética no teatro documentário contemporâneo
}

DANIELE ÁVILA SMALL

Daniele Ávila Small é doutoranda em Artes Cênicas pela UNIRIO (bolsista CAPES), mestre em História Social da Cultura pela PUC-Rio e bacharel em Teoria do Teatro pela UNIRIO. Autora do livro O Crítico Ignorante (Editora 7Letras, 2015) e da peça Garras Curvas e Um Canto Sedutor (Cobogó, 2015). Idealizadora e editora da revista eletrônica Questão de Crítica (www.questaodecritica.com.br).

The essay focuses on the contemporary documentary performance regarding the transmission of historical knowledge on a double perspective: theatre and the production of meaning, history and the production of presence, according to the ideas of German philosopher Hans Ulrich Gumbrecht. In order to accomplish that, two plays are analysed: Um Museu Vivo de Memórias Pequenas e Esquecidas [A Living Museum of Small and Forgotten Memories] by Joana Craveiro, from Lisbon, Portugal, and Guerrilheiras ou Para a Terra não Há Desaparecidos [Guerrilla Women or There Are No Missing People for the Earth] by Gabriela Carneiro da Cunha, from Rio de Janeiro, Brazil.

DOCUMENTARY THEATRE / HISTORIOGRAPHY / MEMORY / PRODUCTION OF MEANING / PRODUCTION OF PRESENCE

Para além de pôr a história em cena, embora certamente o faça, o teatro documentário também tem a capacidade de encenar historiografia. CAROL MARTIN, Dramaturgy of the Real on the World Stage (2010)

A proposta deste breve ensaio é pensar a relação entre o teatro e a história na atualidade a partir de dois espetáculos recentes, Um Museu Vivo de Memórias Pequenas e Esquecidas, da atriz e diretora Joana Craveiro, de Lisboa, e Guerrilheiras ou Para a Terra não Há Desaparecidos, projeto da atriz Gabriela Carneiro da Cunha, do Rio de Janeiro. As duas peças, cada uma ao seu modo, fazem o exercício de olhar para a história a partir do presente. Mesmo com escolhas artísticas radicalmente diferentes, suas formas tão diversas de «encenar historiografia», há questões que aproximam os dois projetos.

Nas peças aqui abordadas, duas artistas foram movidas pela necessidade de olhar para trás e fazer perguntas para a história do seu país. A diferença nos desdobramentos poéticos desse 
movimento do teatro na direção da história é exemplar da não-exemplaridade do teatro documentário contemporâneo. Não há uma poética que identifique essa ampla categoria. O que faz as peças se aproximarem uma da outra é o projeto mesmo de enfrentar a escrita da história, o passado e a memória.

Procuramos pensar a afinidade do gênero com a transmissão de um saber histórico por uma dupla perspectiva: a relação do teatro com a produção de sentido e a relação da história com a produção de presença, de acordo com o pensamento do filósofo alemão Hans Ulrich Gumbrecht.

\section{UM MUSEU VIVO DE MEMÓRIAS PEQUENAS E ESQUECIDAS}

Em junho de 2015, tive a oportunidade de assistir à peça de Joana Craveiro Um Museu Vivo de Memórias Pequenas e Esquecidas, no 38. ${ }^{\circ}$ FITEI - Festival Internacional de Teatro de Expressão Ibérica, no Porto. O espetáculo marcou o epicentro do festival. Marcou também a minha experiência pessoal como brasileira em Portugal. Pela fortuna crítica do espetáculo percebe-se o quanto se destaca esse trabalho do grupo Teatro do Vestido, a relevância artística e cultural da peça e a sua notável repercussão desde a estreia em 2014, ano do 40. ${ }^{\circ}$ aniversário da Revolução dos Cravos, que derrubou a ditadura salazarista em Portugal.

O trabalho é parte da pesquisa de doutoramento de Joana Craveiro na Universidade de Roehampton, em Londres, sobre a política da memória no período posterior à ditadura em Portugal. Ela assina a pesquisa, o texto, a direção e a criação, ou seja, trata-se de um projeto bastante pessoal e autoral, mas que conta com a colaboração criativa e assistência de Rosinda Costa e Tânia Guerreiro. Talvez a relação com a pesquisa acadêmica tenha colaborado positivamente para a precisão dramatúrgica do espetáculo, que tem como fio condutor uma hipótese de pesquisa, a pergunta «quando é que a Revolução acabou?». A pergunta faz referência ao 25 de novembro de 1975, considerado o marco do fim do processo revolucionário. Ao fazer essa pergunta, a pesquisa se mostra interessada em remexer as verdades da história de Portugal e, consequentemente, questiona os modos pragmáticos da historiografia.

Uma questão é fundamental para a noção de teatro documentário da qual estamos tratando: as perguntas de Joana 
Craveiro são feitas pelo ponto de vista de uma geração que não viveu diretamente os fatos de que trata nesse espetáculo - e o mesmo acontece na peça Guerrilheiras. De acordo com Marianne Hirsch (2008), a geração dos descendentes de sobreviventes de eventos traumáticos - que não é testemunha direta desse trauma, mas que recebe essa experiência de outros modos, como pela narrativa familiar particular - é a geração da pós-memória. Hirsch afirma que é possível lembrar-se da memória dos outros através de imagens, objetos, histórias, comportamentos e afetos que são transmitidos no ambiente familiar e cultural. Trata-se de um conceito importante: uma das sete partes da peça é intitulada «Pós-memória».

Assim, podemos perceber que a questão da memória é de antemão colocada por Joana Craveiro como um problema a ser enfrentado. O desejo de lançar um olhar para a história não é o desejo de ler ou ouvir de novo o que já se sabe, mas o desejo de escutar as lacunas e reescrever as narrativas dadas de acordo com o que ficou faltando, o que não ficou registrado - indo na contramão do apagamento da memória e da história.

Sua situação de descendente da memória é a condição de possibilidade do seu olhar. Ela apresenta essa condição como quem coloca as cartas na mesa no prólogo do espetáculo, uma operação em que propõe um ajuste de lentes. Dando início aos trabalhos, apresenta o primeiro documento da sua exposição, um documento particular, praticamente caseiro, uma foto sua quando menina, tirada em 1980 na escola. Ao enfatizar que era criança nos anos 80, está se posicionando quanto ao pertencimento à sua geração.

$\mathrm{Na}$ foto, o fundo detrás da imagem da criança é um painel que representa os Alpes suíços. Joana está ela mesma nesse momento posicionada à frente de um desses painéis, com um quadrinho que diz «Benfica 1980». Ela se pergunta o que a Suíça poderia significar para um país complexado e em crise como o Portugal daqueles anos. Com isso, Joana propõe um questionamento autorreflexivo, em que se pergunta não apenas sobre a condição do seu país, mas sobre a sua autoimagem, sobre aquilo que o país fala e pensa sobre si mesmo, suas narrativas identitárias.

Depois desse breve prólogo, com uma mala em cada mão (uma verde e outra vermelha), ela nos convida a entrar no espaço cênico. A apresentação no FITEI aconteceu no Teatro Nacional São João, que acolheu o espetáculo com arquibancadas montadas sobre 
o palco. No cenário para essa peça-palestra, o espaço da cena é dividido em alguns nichos, com cadeiras, caixas, malas e papéis. Dois armários, uma espécie de arquivo de escritório e um armário que poderia ser o guarda-roupa de alguém: a cenografia parece anunciar que as fontes, os documentos e relatos ali utilizados serão de procedências variadas. A história oficial vai ser atravessada por narrativas particulares, não-oficiais, enfim, anônimas. Ao centro, uma mesa de trabalho, em que Joana Craveiro se posiciona como quem vai estudar. À mesa, livros, cadernos e objetos de uso cotidiano. Entre eles, um pequeno rádio à pilha, elemento discretamente simbólico. Acima da mesa, uma câmera que captura imagens que Joana posiciona, enquanto apresenta sua fala, em um caderno em espiral, com recortes de cópias de trechos de livros, fotos, desenhos, recortes de jornal. Aos poucos, Joana ilustra o caderno, posicionando outras fotos, documentos e livros, que a câmera captura. As imagens são projetadas em uma grande tela ao fundo da cena. Assim, vemos a narrativa historiográfica criada por Joana através da materialidade artesanal da sua pesquisa.

Ao longo de aproximadamente quatro horas e meia, com intervalo para um jantar oferecido pela produção da peça, assistimos a sete palestras performativas, nas quais são abordados períodos e aspectos da história de Portugal desde o início da ditadura na década de 1920. Em «Pequenos Atos de Resistência», Joana conta anedotas de gestos de clandestinidade, dos quais ela afirma que seus pais participavam. Com humor, ela conta a história de uma livraria clandestina e apresenta uma enorme lista de livros e autores proibidos. Em «Arquivos Invisíveis da Ditadura Portuguesa», ela traz à tona os procedimentos de tortura da PIDE (a polícia política da ditadura) e conta a história do estudante Ribeiro Santos, que se tornou um símbolo da resistência e que lembra muito o caso do estudante carioca Edson Luís, assassinado no Rio de Janeiro pelos militares em março de 1968, ano do Ato Institucional n. ${ }^{\circ} 5$. Em «Espantados de Regressar-História de Uma Família», Joana lança mão de arquivos particulares de uma família como documentos para uma narrativa do legado traumático da Guerra Colonial. Os títulos das palestras já dão indícios das operações historiográficas de Joana: os atos são pequenos, os arquivos são invisíveis, as histórias são de família.

Mas, embora o espetáculo seja feito de relatos e exposição de fatos e documentos, a maneira como Joana Craveiro se dirige aos 
espectadores cria uma atmosfera de partilha, o que também se consolida com pequenas estratégias de participação, como, por exemplo, a distribuição de livros que pertencem àquela lista de proibições.

A palestra em que se dá o relato do momento da Revolução dos Cravos, intitulada «Português Entrecortado», recebe um tratamento singular. Joana Craveiro se posiciona em uma lateral do palco, em um nicho cenográfico discreto, tomando para si um microfone e um fone de ouvido. Assumindo um tom de voz diferente, mais aveludado, ela nos conta que os militares armaram o golpe na forma de uma peça encenada. Ela narra os acontecimentos do dia 25 de abril de 1974 privilegiando a teatralidade do evento. Com a voz mais baixa, a iluminação mais suave, Joana oferece a dimensão do acontecimento feito em surdina, na madrugada, e dá ênfase à sua qualidade romântica, ao sonho de liberdade que estava sendo defendido naquele momento. A rádio foi o instrumento de articulação das tropas armadas. Uma primeira senha foi transmitida: a rádio Emissores Associados de Lisboa tocou «E depois do Adeus», uma canção popular que não levantaria suspeitas. Depois, com o movimento avançado, uma segunda senha: a Rádio Renascença tocou «Grândola, Vila Morena», canção proibida pela ditadura. Não apenas ao narrar os acontecimentos, mas por fazê-lo com um tratamento mais teatral, com mais elaboração formal que nas demais palestras, Joana Craveiro parece enfatizar o caráter simbólico da dramaturgia da Revolução.

Não à toa, a música é parte tão importante do espetáculo e instrumento de criação de vínculo da peça com o espectador e dos espectadores entre si. Ao longo de toda a peça, em momentos pontuais, Joana Craveiro coloca um disco em uma vitrola (gira-discos, devo dizer). Muitos espectadores acompanham, cantando junto. Nesses momentos, minha experiência pessoal com a peça ficou muito marcada, pois ali percebi o quanto eu, brasileira da geração da pós-memória da ditadura do meu país, pouco sabia da história da ditadura do país que colonizou o meu. Mas, ao ouvir os relatos de repressão, violência de Estado e abusos de autoridade, dos pequenos gestos de resistência e das histórias invisíveis, que por espelhamento pareciam tão familiares; ao ouvir, ao mesmo tempo, as pessoas cantarem à minha volta, me dava conta (pela primeira vez de fato) do vínculo e da sensação complexa de pertencimento que nós, brasileiros, temos com Portugal. 
No sítio do Teatro do Vestido, uma passagem sintetiza o movimento, por parte dos artistas, de assumir a responsabilidade sobre as narrativas históricas que lhe dizem respeito:

Em Portugal, na ausência de uma Comissão da Verdade e Justiça, ou algo semelhante, são os activistas, os cientistas sociais, os historiadores, bem como os artistas, quem tem levado a cabo esse paciente trabalho de reconstituição, contra a usura do tempo e das ideologias vigentes que, cada qual à sua maneira e de acordo com a sua agenda, têm procurado - mais do que estabelecer pontos de vista - reescrever a história.

Mas acredito que essa reescrita da história não é apenas de um trabalho de reconstituição. O que vemos em Um Museu Vivo de Memórias Pequenas e Esquecidas e em outras peças de teatro documentário contemporâneo ${ }^{2}$ é outra natureza de transmissão do saber histórico. Uma questão importante a se colocar aqui, por exemplo, embora evidente e nada original, é o resgate (se posso usar essa palavra) da oralidade na transmissão do saber histórico. Não me refiro apenas à oralidade da sala de aula, à eficácia da partilha de conhecimento que acontece entre professor e aluno na escola, mas à cultura ancestral que a sociedade ocidental esqueceu e que o teatro reivindica para si. A música, como dissemos, tem um papel determinante na costura dos relatos na memória e na experiência do espectador. E a música não acontece nos livros.

\section{GUERRILHEIRAS OU PARA A TERRA NÃO HÁ DESAPARECIDOS}

Do outro lado do oceano Atlântico, outra ditadura. Guerrilheiras ou Para a Terra não Há Desaparecidos estreou em setembro de 2015 na arena do Espaço Sesc. A Guerrilha do Araguaia, tema central da peça em questão, é um episódio singular entre os inúmeros episódios de violência dos militares contra a luta armada durante a ditadura no Brasil. Aconteceu numa região situada entre os estados do Pará e o atual Tocantins ${ }^{3}$ na floresta amazônica, reunindo cerca de setenta guerrilheiros, sendo dezessete mulheres, que saíram de diversas cidades do país para participar do movimento que

1 http://teatrodovestido.org/blog/?p=5334.

2 Entre alguns exemplos, posso citar (entre peças a que assisti, sabendo que há muitas outras) Mi vida después e Melancolía y manifestaciones, de Lola Arias, da Argentina; Galvarino (parte de uma trilogia de teatro documentário), do Teatro Kimen, do Chile; El rumor del incêndio e Derretiré con un cerrillo la nieve de un volcán, do grupo Lagartijas Tiradas al Sol, do México; Luiz Antônio-Gabriela de Nelson Baskerville, de São Paulo e Jacy, do Grupo Carmin, de Natal, ambos do Brasil. $\mathrm{Na}$ época da Guerrilha do Araguaia, ainda não havia o Tocantins, estado criado em 1988. 
pretendia derrubar a ditadura e tomar o poder cercando as cidades pelo campo. De abril de 1972 a janeiro de 1975, o regime militar mobilizou cerca de cinco mil homens para estancar o movimento. A ordem para os soldados era que nenhum guerrilheiro fosse preso, ou seja, todos deveriam ser assassinados. Não deveria haver sobreviventes porque foi estabelecido que a guerrilha não poderia deixar rastros. Processos judiciais foram retirados para que não houvesse registro de menção à Guerrilha do Araguaia, como ficamos sabendo pelo depoimento do deputado Haroldo Lima, do Partido Comunista do Brasil (PCdoB), no debate realizado após uma das sessões da peça. ${ }^{4}$

A montagem traz à tona a violência deliberada contra a memória, para além do massacre sofrido pelos guerrilheiros. E o gesto de realização do projeto espelha o gesto da guerrilha em si. Conta-se que um dos arquitetos do Araguaia, João Amazonas, dizia que o Araguaia não era uma luta para derrubar a ditadura naquele momento, mas um gesto para a humanidade.

$O$ projeto de Gabriela Carneiro da Cunha estabelece um diálogo entre criação ficcional e documentário para reativar a memória dessa parte obscura (de tantas partes tão obscuras) da ditadura militar no Brasil. A peça, que foi chamada de poema cênico pelas artistas criadoras, se concentra nas histórias das mulheres cujos corpos ainda hoje estão desaparecidos. Das doze guerrilheiras desaparecidas, apenas uma delas teve seus restos mortais encontrados.

Para a realização do espetáculo, equipe e elenco se instalaram na cidade de Xambioá para conhecer a região, as famílias, as histórias do Araguaia e realizar in loco a primeira parte dos ensaios. O cineasta Eryk Rocha acompanhou o processo e registrou imagens que compõem o material fílmico da peça. O grupo também contou com o apoio do ativista Paulo Fonteles Filho, conhecedor da história em questão.

Sem um texto prévio, a peça foi criada no processo de ensaios com as atrizes Gabriela Carneiro da Cunha (do Rio de Janeiro), Carolina Virgüez (de origem colombiana), Daniela Carmona (de Porto Alegre), Fernanda Haucke, Mafalda Pequenino e Sara Antunes 
(as três nascidas no estado de São Paulo) e a diretora (também paulista) Georgette Fadel, sendo a dramaturgia finalizada por Grace Passô (de Belo Horizonte). A equipe de criação é proveniente de diferentes cidades do Brasil, um detalhe que deve ser levado em consideração, tendo em vista que as guerrilheiras de que a peça fala também se reuniram a partir de diferentes cidades do Brasil.

A peça lança mão de depoimentos gravados, com as vozes de moradores da região, e de depoimentos falados pelas atrizes, ou seja, depoimentos recortados de seus contextos e reorganizados em uma dramaturgia. A fragmentação de Guerrilheiras é consequência da fragmentação da informação e da própria narrativa histórica que é o objeto de estudo da peça: um passado em frangalhos, um quebra-cabeças com quase todas as peças faltando. Alguns depoimentos recolhidos pelas atrizes-pesquisadoras foram concedidos pela primeira vez. A presença das artistas na cidade, a forma como as pessoas foram abordadas, tudo isso contribuiu para que as conversas fossem conquistadas, para que algumas pessoas se pusessem a falar - afinal, o medo não é coisa do passado.

No entanto, vale observar que o espetáculo alcança seus momentos mais potentes quando tende à criação de imagens abstratas, momentos mais líricos, em que a visualidade se sobrepõe à ânsia pela dramatização dos fatos e, assim, são criadas imagens que evocam a presença fantasmática daquelas mulheres na paisagem amazônica.

A cenografia de Aurora dos Campos contempla as duas linguagens em que a peça se escora: de um lado, uma peça criada por improvisações e jogos teatrais, do outro lado, uma ideia de teatro em franco diálogo com o cinema. Na arena, o chão está coberto com um linóleo vermelho sobre o qual se projetam as imagens filmadas. Ao longo do espetáculo, o chão vai sendo coberto por camadas de imensas folhas de plástico de diferentes cores. As atrizes manipulam outras folhas de plástico, inclusive grandes sacos de plástico transparente, abertos nas duas extremidades que, tendo a medida da estatura humana, são usados para apresentar os corpos dessas mulheres como cadáveres. Em alguns momentos elas se colocam dentro dos sacos e se deitam no chão, criando imagens das mulheres mortas embaixo da terra e do rio.

As camadas de plástico remetem às camadas da memória e do esquecimento - porque são muitas as camadas de 
silenciamento da história no Brasil. $\mathrm{E}$ também às camadas de terra que escondem os corpos. A iluminação joga com as cores complementares sobre o plástico, o que pode ter alguma relação com a verdade sempre relativa dos fatos e relatos da história. E o teatro mesmo, quando atrelado ao discurso historiográfico, ao saber histórico, acrescenta ao conhecimento uma camada de memória de outra natureza - e essa outra natureza de memória e de saber me parece ser o que o teatro documentário contemporâneo tem a oferecer à escrita da história.

Guerrilheiras, como Um Museu Vivo, também traz depoimentos de anônimos, invisíveis. Mas os anônimos que podem relatar os rastros das desaparecidas não são anônimos no sentido do «qualquer um» kantiano, nem são metaforicamente invisíveis, são habitantes de uma região propositalmente silenciada e feita invisível por uma situação de violência policial que, mesmo com o fim da ditadura, nunca deixou de existir. A sensação de viver sob uma ditadura militar não acabou em todo o Brasil: as liberdades não são as mesmas para todas as classes sociais e o aparato policial-militar ainda exerce um poder inaudito em determinadas regiões do Brasil como a que está sendo tratada nessa peça.

O desenho sonoro também tem uma função importante em Guerrilheiras: nesse caso, não são somente as músicas tocadas que estabelecem uma relação de presença e pertencimento, mas os trechos de canções cantadas pelas atrizes quando estão no lugar das desaparecidas, e os sons que acompanham as imagens capturadas no sul do Pará. A produção de imagens visuais não-discursivas permite que a peça se descole do aqui e agora do teatro e vá atrás do contato com uma história que ficou embaixo da terra. Como diz a segunda parte do título, «para a terra não há desaparecidos». Graças às imagens criadas na peça com a direção audiovisual de Eryk Rocha, a cenografia de Aurora dos Campos, a iluminação de Tomás Ribas e a trilha sonora de Felipe Storino, o espetáculo alcança a operação poética de contar a história do ponto de vista da terra: elas não estão desaparecidas porque estão lá, como sementes, na floresta da história. Foram assassinadas para que desaparecessem, mas a presença dos seus rostos (nas fotos projetadas no chão do palco) e dos seus corpos (nos corpos das atrizes dentro dos sacos plásticos) reaparecem no esforço criativo-historiográfico da construção dessas imagens no teatro. 
A relação do teatro com a historiografia não é novidade, naturalmente. Mas, praticamente um século depois das primeiras peças de Erwin Piscator, estamos falando sobre teatro documentário com interesse bastante renovado. No entanto, parece haver um mal-estar diante da ideia do teatro como lugar de articulação ou partilha de saberes.

Em determinados segmentos do teatro, defende-se que o teatro não precisa servir a nada, que não cabe ao teatro transmitir uma mensagem - premissa com a qual concordo plenamente. Mas, diante dessas e de outras peças afins a que assisti recentemente, tal premissa se abala: esses espetáculos têm também um lugar no mundo como acontecimento culturals, para além do seu lugar autônomo de obras de arte, e têm alguma relação com a ideia de «mensagem», a besta negra do teatro contemporâneo.

Pensando assim, estamos concebendo uma separação radical entre a experiência estética, a fruição da arte, de um lado, e o conhecimento do mundo, a reflexão sobre as coisas do mundo, de outro. Acredito que essa separação é uma ficção.

Em seu livro Produção de Presença: O Que o Sentido não Consegue Transmitir, Gumbrecht critica a busca praticamente exclusiva de sentido na apreensão dos fenômenos, o que ele percebe como uma forma predominante da lida com os saberes nas Humanidades, algo que diz respeito a uma hierarquia que determina que $o$ sentido espiritual, ou seja, a interpretação (profunda) é superior à experiência ligada à corporeidade, à (supostamente superficial) materialidade das coisas. Ele chama a atenção para as coisas (como as obras de arte, gestos ou acontecimentos que apreendemos esteticamente) que não têm nenhuma «utilidade» ou «sentido» estrito, mas que percebemos pela sua dimensão de presença, pela intensidade que catalisam em nós.

Os objetos estéticos abordados nessa pesquisa têm uma ligação direta com o sentido, mas, mesmo quando o objeto traz em si uma ênfase na demanda de apreensão de um conteúdo, essa não é necessariamente uma dimensão exclusiva.

As peças abordadas nesse estudo articulam sentidos, mas o fazem pela relação de presença no acontecimento espaçotemporal 
do fato teatral e não têm como objetivo a transmissão de um saber no sentido pedagógico. A lida do espectador com essas obras não se dá exclusivamente de modo intelectual-interpretativo. As pessoas não vão ao teatro para «aprender» a história de Portugal nem da Guerrilha do Araguaia. E, mesmo se assim fosse, o modo intelectual-interpretativo não é um modo exclusivo de apreensão do saber histórico.

Gumbrecht defende que o sentido não é a única condição de produção de conhecimento nas Humanidades: «Sugere-se, por exemplo, que concebamos a experiência estética como uma oscilação (às vezes, uma interferência) entre "efeitos de presença" e "efeitos de sentido" » (2010: 22). A aproximação do teatro com a narrativa histórica é uma evidência praticamente literal dessa possibilidade, tendo em vista a copresença dos corpos no espaço e um entendimento do teatro que não tem expectativa de sentido. Mas Gumbrecht se refere ao teatro apenas numa perspectiva histórica ampla demais - e sem presente. Ele aponta um momento da história do teatro em que, no início da modernidade, a cortina foi inserida para separar os corpos dos atores e dos espectadores, inventando-se assim um teatro com sentidos ocultos e complexos que deveriam ser interpretados por aqueles que estão do outro lado da cena. A essa forma de teatro (que coincide com o movimento que ele descreve em que se dá a tendência das Humanidades a se fechar na hermenêutica), ele opõe o teatro medieval e a commedia dell'arte, em que a relação central é a de uma espécie de coreografia dos corpos dos atores em um espaço que não é separado dos corpos dos espectadores. Na história do teatro que ele apresenta, deu-se um movimento único que passou de um ritual de produção de presença, de uma materialidade corpórea efetiva, a uma predominância do cogito cartesiano.

Infelizmente, Gumbrecht não reflete sobre a complexidade das formas do teatro na atualidade, o que provavelmente resultaria numa análise interessante, porque é justamente pela relação dialética entre produção de sentido e produção de presença que o teatro que estamos querendo estudar neste ensaio pode ser exemplar para pensar a sua hipótese.

A questão é que as peças que «encenam historiografia» são, acima de tudo, peças de teatro. Seu propósito é a experiência estética. As palestras de Joana Craveiro são palestras performativas, não são simplesmente palestras. O público está lá na condição de espectador 
de teatro, não de aluno ou pesquisador. $\mathrm{O}$ fato de que há conteúdo historiográfico na peça, informação sobre fatos, pessoas, datas, o fato de que há pensamento sobre o mundo, nada disso anula a experiência estética nem transfere a peça para um âmbito não-artístico.

Toda experiência estética tem uma dimensão de sentido e uma dimensão de presença. Talvez Um Museu Vivo tenha uma aparente ênfase na produção de sentido, por conta da forma do discurso textual. Talvez Guerrilheiras tenha uma ênfase na produção de presença, pela natureza fragmentada das informações transmitidas, pela convivência simultânea com a criação ficcional e pela criação de imagens abstratas. Mas os diferentes agenciamentos de conteúdos não se anulam mutuamente. Os componentes de sentido e de presença convivem em uma relação pendular, dialética. Nesse sentido, aquela separação radical entre a experiência estética, a fruição da arte e o conhecimento do mundo, o pensamento sobre o mundo, fica um tanto embaçada.

Gumbrecht vai se perguntar como o conceito de presença pode ter um impacto nos modos de ensinar história e de fazer pesquisa histórica. Ou seja, ele vai se perguntar sobre a relação entre a experiência estética (que não tem propósito) e a perspectiva da transmissão da história (que se acredita uma coisa útil). Ele responde questionando o enunciado mesmo da pergunta, esclarecendo que a nossa relação com a história não é necessariamente a da expectativa de um aprendizado útil, tendo em vista que o desejo de presentificação do passado não se dá (ou não se dá mais) por uma crença de que podemos aprender com ele. Sabemos que o topos historia magistra vitae 6 não é mais uma premissa na lida com a história.

Uma resposta possível toma como ponto de partida a sensação de que nossa ânsia de preencher o sempre crescente presente com artefatos do passado pouco tem a ver - se é que tem algo a ver - com o projeto tradicional de interpretar (ou seja, de reconceitualizar) o nosso conhecimento sobre o passado ou com o objetivo de «aprender com a história».

(Gumbrecht, 2010: 151)

$\mathrm{O}$ «sempre crescente presente» diz respeito a uma noção de tempo presente que não é mais comprimida entre uma ideia de passado 
que está sendo deixado para trás e um futuro que está bloqueado, ou seja, trata-se de uma percepção mais ampla do tempo presente, que acumula mundos passados. $O$ desejo de presentificação do passado que, segundo ele, é subjacente a todas as culturas históricas diz respeito à vontade humana de ultrapassar a fronteira do nosso nascimento e à possibilidade de «falar com os mortos, de tocar os objetos de seus mundos», talvez como um desejo de dar as costas ao futuro que nos aguarda com a finitude da vida.

Diante dessa ideia, não há razão para questionar um possível «desvio utilitário» do teatro documentário, já que nossa relação com o passado não é a de uma demanda de aprendizado, mas um desejo de alargamento do presente, um impulso humano que também pode ter o seu lugar entre os despropósitos. Não há ganhos práticos da história para a vida - nem para o teatro. E, mesmo quando o teatro se avizinha dos modos discursivos da história ou da filosofia ou até da matemática, não importa: o teatro continua sendo, acima de tudo, teatro.

Quanto aos ganhos práticos da experiência estética para a história, assunto que já foi experimentado em outro artigo 7 , mas que lá tomou outro caminho, podemos responder que o teatro é, como Gumbrecht gostaria que fosse o ensino das Humanidades, um «catalisador de eventos intelectuais» por natureza. O teatro oferece a ênfase na dimensão da presença, a linguagem artística oferece a possibilidade de criar «intensidades concentradas» (para usar uma conceituação de Gumbrecht para a experiência estética), produzindo epifanias a partir de imagens e sons que não demandam interpretação nem precisam ter um sentido - e que a materialidade racional do discurso historiográfico talvez não seja capaz de provocar.

Além disso, em vez de optar pelo apagamento daquele que escreve, aspecto comum da escrita historiográfica, o teatro documentário põe em cena um corpo-historiador, que está no aqui e agora do espaço cênico tecendo a narrativa diante dos olhos e dos corpos dos espectadores. Essa corporeidade do enunciador confere uma estatura humana para a história, o que contribui para a ideia de uma produção de presença. 
Há ainda outro aspecto a ser abordado sobre o teatro documentário contemporâneo, mas que será apenas apontado, como um apêndice para conversas futuras. Podemos pensar o teatro - a título de exercício teórico - como uma prática que pode ter se encastelado e que assim se aproxima de uma ideia de «perda de mundo». Aqui me refiro ao fato de que o teatro não é uma «coisa pública», mas uma prática de um nicho artístico que tem um público restrito e nenhum impacto sobre a vida cotidiana. «Perda de mundo» é a expressão usada por Gumbrecht para uma sensação de que as Humanidades não estão mais em contato com o mundo. É claro que também podemos nos perguntar se é possível que qualquer coisa esteja em contato com o mundo, já que a ideia mesma de mundo é algo muito difícil de se apreender e que a fragmentação da esfera pública é um fenômeno que data, pelo menos, do século XIX.

Mas vamos seguir com a ideia de «perda de mundo» como um exercício teórico para pensarmos a relação do teatro com um público mais amplo, não especializado, e para pensar o teatro para além de uma arte autorreferente e autorreflexiva, ou para além da distração alienada de apelo popular.

Essa sensação de perda de mundo não é consequência de uma incapacidade das formas atuais do teatro, nem de uma mera falta de informação por parte do público (especialmente dos intelectuais das Humanidades!), que sequer sabe que existe um teatro que se faz hoje em dia e que muito lhes interessaria, mas de uma complexa condição histórica a que estamos presos e da qual realmente não sabemos como sair.

Os espetáculos como os que analisamos brevemente aqui mobilizam setores da sociedade que ultrapassam o círculo restrito de espectadores de teatro, o que ficou claro para mim nos debates que aconteceram depois da apresentação de cada uma das peças e dos quais participaram pessoas de outras áreas, ou seja, que não são «de teatro». Esse é um grande feito e algo a se pensar sobre o teatro documentário. Os dois trabalhos são peças que, como costumo dizer, «estão no mundo».

Essa dimensão mais ampla do alcance dessas obras nos faz ver o teatro como coisa pública, não como um nicho isolado das artes - ainda que sua relação com a produção de sentido não seja uma possibilidade única, nem predominante, na relação com o espectador. 


\section{REFERÊNCIAS BIBLIOGRÁFICAS}

FIGUEIRA, Jorge Louraço (2014), «Riachos, ribeiros e outros afluentes da revolução», Público, 16 de novembro.

GUMBRECHT, Hans Ulrich (2010), Produção de Presença: O Que o Sentido não Consegue Transmitir, Rio de Janeiro, Contraponto, Editora PUC-Rio.

HIRSH, Marianne (2008), «The Generation of Postmemory», in Poetics Today, 29:1, pp. 103-128.

KOSSELlE CK, Heinhart (2006), Futuro Passado: Contribuição à semântica dos tempos históricos, tradução do original alemão de Wilma Patrícia Maas e Carlos Almeida Pereira, Rio de Janeiro, Contraponto, Editora PUC-Rio.

MARTIN, Carol (2010), Dramaturgy of the Real on the World Stage (Studies in International Performance), Londres, Palgrave MacMilan.

SMALL, Daniele Ávila (2010), «Atos físicos da memória, re-inscrições na História - Crítica de Mi vida después, de Lola Arias», Questão de Crítica, vol. III, n.o 26, outubro, http://www.questaodecritica.com. br/2010/10/atos-fisicos-da-memoria-re-inscricoes-na-historia/.

-- (2014), «Com um palito de fósforo - Intervenções teatrais na escrita da história», Questão de Crítica, vol. viI, n. ${ }^{\circ}$ 63, dezembro, http://www.questaodecritica.com.br/2014/12/com-um-palito-defosforo-intervencoes-teatrais-na-escrita-da-historia/. 